\title{
Perbandingan Kualitas Layanan Kefarmasian Di Puskesmas Berstandar Iso Dan Non-ISO Kota Denpasar
}

\author{
Jaya, M.K.A ${ }^{1}$, Dewi, N.L.S ${ }^{2}$, Rudiartha, I.G.L.M ${ }^{2}$ \\ ${ }^{1}$ Program Studi Farmasi, Fakultas Matematika dan Ilmu Pengetahuan Alam, Universitas Udayana, \\ Jalan Kampus Unud, Jimbaran, Badung-Bali, 80364 \\ ${ }^{2}$ Program Studi Farmasi Klinis, Universitas Bali Internasional, Jalan Seroja, Gang Jeruk, Tonja, \\ Denpasar-Bali, 80234 \\ *E-mail: krisnaadijaya@unud.ac.id \\ Riwayat artikel: Dikirim: 26/07/2020; Diterima: 18/12/2020, Diterbitkan: 1/07/2021
}

\begin{abstract}
Primary Health Care is a facilitiesus to improve health status and health development. Pharmaceutical services at puskesmas are always in the spotlight of the community and tend to be negative in stigma. The community paradigm, especially in Denpasar, tends to state that pharmaceutical services at ISOstandard puskesmas are better than non-ISO. However, this does not mean that non-ISO health centers in Denpasar City do not provide optimal services to the community. Based on this problem, research needs to be conducted to assess the extent of differences in the quality of pharmaceutical services in ISO and non-ISO health centers in Denpasar. This study aims to compare the quality of pharmaceutical services in ISO and non-ISO puskesmas including the waiting time for drug services, the incidence of Drug Related Problems (DRP), and the level of patient satisfaction. An analytic observational study was conducted by observing 184 respondents who used the health services at the puskesmas in Denpasar. Waiting time was observed from the patient submitting a prescription until getting the medicine; DRP was observed by the number of drug interactions, patient adherence to therapy and the incidence of Adverse Drug Reaction (ADR); and patient satisfaction using the satisfaction questionnaire. The waiting time for drug services showed that the ISO puskesmas was superior to non-ISO ( $\mathrm{p}<0.05)$ while the DRP incidence and patient-related satisfaction were not significantly different ( $p>0.05$ ). Non-ISO Puskesmas in Denpasar showed the quality of pharmaceutical services that were comparable to Puskesmas with ISO standards.
\end{abstract}

Keywords: Drug Services, Drug Related Problem, Patients Satisfaction, Primary Health Care

\begin{abstract}
ABSTRAK
Puskesmas merupakan sarana yang digunakan untuk meningkatkan derajat kesehatan dan merupakan ujung tombak pembangunan kesehatan. Pelayanan kefarmasian di puskesmas selalu menjadi sorotan dari masyarakat dan cenderung berstigma negatif. Paradigma masyarakat khususnya di Kota Denpasar cenderung menyatakan bahwa pelayanan kefarmasian di puskesmas yang berstandar ISO lebih baik dibandingkan dengan non ISO. Akan tetapi hal ini bukan berarti bahwa puskesmas non-ISO di Kota Denpasar tidak memberikan pelayanan yang optimal kepada masyarakat. Berdasarkan hal tersebut perlu dilakukan penelitian untuk menilai seberapa jauh perbedaan kualitas layanan kefarmasian di puskesmas ISO dan non-ISO Kota Denpasar. Penelitian ini bertujuan untuk membandingkan kualitas layanan kefarmasian di puskesmas berstandar ISO dan non-ISO meliputi waktu tunggu pelayanan obat, angka kejadian Drug Related Problem (DRP), dan tingkat kepuasan pasien. Studi observasional analitik dilakukan dengan mengobservasi 184 responden yang menggunakan layanan kesehatan puskesmas di Kota Denpasar dengan luaran kualitas pelayanan kefarmasian. Waktu tunggu dilihat dari pasien menyerahkan resep sampai mendapatkan obat, DRP dilihat angka kejadian interaksi obat, kepatuhan pasien terhadap terapi dan kejadian Adverse Drug Reaction (ADR), serta kepuasan pasien menggunakan kuisioner kepuasan. Waktu tunggu pelayanan obat menunjukkan bahwa puskesmas ISO
\end{abstract}


DOI : https://doi.org/10.24843/JFU.2021.v10.i01.p06

pISSN: 2301-7716; eISSN: 2622-4607

Jurnal Farmasi Udayana, Vol 10, No 1, Tahun 2021, 48 - 54

lebih unggul dibandingkan non-ISO $(\mathrm{p}<0,05)$ sedangkan variabel kejadian DRP dan terkait kepuasan pasien tidak berbeda signifikan $(p>0,05)$. Kesimpulan: Puskesmas non-ISO di Kota Denpasar menunjukkan kualitas layanan kefarmasian yang kompetetif atau sebanding dengan puskesmas berstandar ISO.

Kata kunci: Pelayanan Obat, Drug Related Problem, Kepuasan Pasien, Puskesmas

\section{PENDAHULUAN}

Kesehatan adalah hak dan investasi semua warga negara. Dalam rangka meningkatkan derajat kesehatan masyarakat Indonesia, upaya yang dilakukan oleh Pemerintah yakni melalui Puskesmas (Permenkes, 2014). Pusat Kesehatan Masyarakat adalah Unit Pelaksana Teknis Dinas Kesehatan Kabupaten/Kota yang merupakan sarana yang menjadi ujung tombak pembangunan kesehatan yang langsung memberikan pelayanan kesehatan terhadap masyarakat di wilayah kerjanya (Aryani et al., 2016).

Puskesmas perlu memiliki daya saing unggul agar selalu diminati oleh masyarakat pengguna jasanya. Salah satu pelayanan kesehatan yang diberikan oleh Puskesmas yakni pelayanan kefarmasian. Namun kenyataannya gambaran situasi dan kondisi pelayanan di bidang kesehatan saat ini cukup memprihatinkan sehingga masyarakat banyak yang tidak puas. Salah satu contohnya yakni berdasarkan hasil observasi di UPTD Puskesmas Pesantren 1 Kota Kediri diketahui saat bulan September 2017 waktu tunggu pasien menjadi lama karena pasien yang berkunjung banyak, pemberkasan yang dilakukan sangat banyak. Keterlambatan tersebut membuat pelayanan ataupun tindakan yang akan diberikan menjadi lambat (Nugraheni, 2017). Selain itu menurut penelitian Niquille dan Bugnon (2010) menunjukkan hasil dari 85 pasien sebanyak 91\% pasien memiliki setidaknya satu DRP. Penelitian lain menunjukkan bahwa 59\% pasien hipertensi mengalami DRPs pada pengobatannya. Ketidakpuasan masyarakat ini harus segera ditindaklanjuti sehingga dapat meningkatkan kepuasan pasien khususnya di bidang kefarmasian. Salah satu cara meningkatkan kepuasan masyarakat adalah dengan menerapkan standar ISO. Terdapat 4 Puskesmas yang sudah menerapkan ISO di Kota Denpasar yakni Puskesmas II Denpasar Selatan, Puskesmas III Denpasar Selatan, Puskesmas IV Denpasar Selatan dan Puskesmas II Denpasar Barat. Puskesmas lainnya di Kota Denpasar yang belum memiliki standarisasi ISO bukan berarti tidak memberikan pelayanan kesehatan yang optimal. Berdasarkan hal tersebut, perlu dilakukan penelitian untuk menilai seberapa jauh perbedaan kualitas layanan puskesmas ISO dan non-ISO di Kota Denpasar, dengan harapan penelitian ini dapat memberikan gambaran apakah standarisasi puskesmas ISO diperlukan untuk seluruh puskesmas atau justru sebaliknya.

\section{METODE}

Penelitian ini merupakan penelitian observasional analitik, dimana dilakukan perbandingan terhadap kualitas layanan puskesmas berstandar ISO dan non ISO di Kota Denpasar-Bali. Populasi pada penelitian ini adalah pasien rawat jalan di salah satu berstandar ISO dan non-ISO di Kota Denpasar. Penelitian ini membutuhkan minimal 100 responden yang terbagi menjadi 50 responden masing-masing pada puskesmas bersandar ISO dan non-ISO.

Teknik pengambilan sampel dengan teknik non probability sampling. Luaran yang diamati sebagai kualitas layanan dalam penelitian ini adalah waktu tunggu pelayanan obat atas resep dokter (dilihat dari pasien menyerahkan resep sampai mendapatkan obat), DRP (dilihat dari kejadia interaksi obat 
yang di bantu oleh aplikasi Medscape, adverse drug reaction yang dievaluasi dengan menggunakan Naranjo scale dan aplikasi Medscape, serta kepatuhan terapi yang dievaluasi menggunakan kuisioner MMAS), dan kepuasan pasien menggunakan kuisioner dari Permenkes RI no 74 Tahun 2016 tentang Standar Pelayanan Kefarmasian di Puskesmas dengan melihat 8 dimensi kepuasan, antara lain: dimensi ketanggapan tenaga kefarmasian terhadap pasien, dimensi keramahan tenaga kefarmasian terhadap pasien, dimensi kejelasan tenaga kefarmasian memberikan informasi obat, dimensi kecepatan pelayanan obat, dimensi kelengkapan obat dan alat kesehatan, dimensi kenyamanan ruang tunggu, dimensi kebersihan ruang tunggu, dan dimensi ketersediaan brosur, leaflet, poster sebagai informasi obat/kesehatan.
Analisis data normal dan homogen digunakan independent t-tes, sedangkan data tidak normal dan tidak homogen digunakan uji non parametrik Chi Square, Mann Whitney atau Kruskall Wallis.

\section{HASIL}

\section{a. Karakteristik demografi responden}

Selama periode penelitian, 184 pasien berhasil diobservasi dengan distribusi masing-masing 92 responden pada puskesmas ISO dan non ISO. Data secara terperinci disajikan pada tabel 1. Seluruh karakteristik responden yang diobservasi dalam penelitian ini memiliki kesamaan karakteristik $(p>0,05)$. Secara umum dapat dinyatakan bahwa responden dalam penelitian ini berangkat dari karakteristik yang seragam. Hal ini akan meminimalisir bias dalam pengukuran luaran penelitian.

\section{Tabel 1. Karakteristik Sosio-demografi Responden}

\begin{tabular}{|c|c|c|c|c|c|}
\hline No. & Karakteristik Dasar & ISO & Non-ISO & p-value & Jenis Analisis \\
\hline 1. & $\begin{array}{l}\text { Jenis Kelamin }(\mathbf{n = 9 2}) \\
\text { Laki-Laki } \\
\text { Perempuan }\end{array}$ & $\begin{array}{l}43(46,8 \%) \\
49(53,2 \%)\end{array}$ & $\begin{array}{l}44(47,8 \%) \\
48(52,2 \%)\end{array}$ & $0,883 \mathrm{NS}$ & Chi-Square \\
\hline 2. & Usia (tahun) $(n=92)$ & $58,77 \pm 11,82$ & $61,27 \pm 11,98$ & $0,156 \mathrm{NS}$ & $\begin{array}{c}\text { Independent } \\
\text { Samples t-test }\end{array}$ \\
\hline 3. & Jumlah Obat (jenis) $(\mathrm{n}=92)$ & $2,30 \pm 0,87$ & $2,59 \pm 1,08$ & $0,068 \mathrm{NS}$ & Mann-Whitney \\
\hline 4. & $\begin{array}{l}\text { Diagnosa }(\mathbf{n = 9 2}) \\
\text { Diabetes Melitus } \\
\text { Hiperlipid } \\
\text { Hiperurisemia } \\
\text { Hipertensi }\end{array}$ & $\begin{array}{c}28(25,2 \%) \\
14(12,6 \%) \\
2(1,80 \%) \\
67(60,4 \%)\end{array}$ & $\begin{array}{r}31(30,4 \%) \\
6(5,90 \%) \\
4(3,90 \%) \\
61(59,8 \%)\end{array}$ & $0,625 \mathrm{NS}$ & Kruskal Wallis \\
\hline
\end{tabular}

Keterangan: $\mathrm{n}=$ jumlah responden; $\mathrm{NS}=$ not significant (tidak signifikan)

\section{b. Waktu Tunggu Pelayanan Obat}

Waktu tunggu pelayanan obat merupakan parameter yang menjadi sangat penting dalam mengukur kualitas layanan. Semakin singkat waktu tunggu pelayanan obat maka semakin baik dan semakin puas persepsi masyarakat terhadap layanan di puskesmas (Aryani et al., 2016). Tabel 2 menujukkan hasil observasi waktu tunggu pelayanan obat atas resep dokter di puskesmas berstandar ISO dan non ISO. Waktu tunggu pelayanan obat pada puskesmas berstandar ISO lebih singkat dibandingkan dengan non-ISO $(\mathrm{p}<0,05)$, sehingga hasil ini memberikan gambaran bahwa puskesmas berstandar ISO lebih unggul dalam hal kecepatan pelayanan obat atas resep dokter.

\section{c. Drug Related Problem (DRP)}

Kejadian DRP yang diobservasi dalam penelitian ini adalah kejadian interaksi obat, kepatuhan terapi obat, dan kejadian ADR. Luaran ini dipilih sebagai DRP karena parameter tersebut paling mudah diobservasi secara langsung. Hasil observasi terhadap luaran DRP disajikan pada tabel 3, 4, dan 5. Hasil analisis pada variabel DRP menunjukkan hasil yang tidak berbeda signifikan ( $p>0.05)$. Hasil ini menggambarkan bahwa baik puskesmas ISO dan non-ISO tidak memiliki perbedaan kualitas layanan dalam hal 
kejadian DRP pada pasien. Analisis terhadap kejadian ADR dalam penelitian ini tidak dapat dilakukan karena tidak terdapat kejadian ADR yang muncul selama periode penelitian.

Tabel 2. Waktu Tunggu Pelayanan Obat Atas Resep Dokter di Puskesmas ISO dan Non-ISO

\begin{tabular}{lcccc}
\hline \multirow{2}{*}{ Lokasi Observasi } & \multicolumn{3}{c}{ Parameter } \\
\cline { 2 - 5 } & $\begin{array}{c}\text { Waktu Tunggu } \\
\text { Rata-rata (menit) }\end{array}$ & $\begin{array}{c}\text { Standar Deviasi } \\
\text { (SD) }\end{array}$ & p-value & $\begin{array}{c}\text { Jenis } \\
\text { Analisis }\end{array}$ \\
\hline Puskesmas ISO (n=92) & 1.46 & \pm 0.64 & $<0,05$ & Mann- \\
\hline Puskesmas Non-ISO (n=92) & 2.31 & \pm 0.68 & Sig & Whitney U \\
\hline Kenn
\end{tabular}

Keterangan: $\mathrm{n}=$ jumlah responden; Sig=signifikan

Tabel 3. Kejadian Interaksi Obat

\begin{tabular}{lcccc}
\hline \multirow{2}{*}{ Parameter } & \multicolumn{4}{c}{ Puskesmas } \\
\cline { 2 - 3 } & ISO $(\mathbf{n = 9 2 )}$ & Non-ISO (n= 92) & p-value & Jenis Analisis \\
\hline Terjadi Interaksi Obat & $11(11,96 \%)$ & $19(20,66 \%)$ & 0,110 & \multirow{2}{*}{ Chi-Square } \\
\hline Tidak Terjadi Interaksi Obat & $81(88,04 \%)$ & $73(79,34 \%)$ & NS & \\
\hline Kenn
\end{tabular}

Keterangan: $\mathrm{n}=\mathrm{jumlah}$ responden; $\mathrm{NS}=$ not significant (tidak signifikan)

Tabel 4. Tingkat Kepatuhan Minum Obat

\begin{tabular}{|c|c|c|c|c|}
\hline \multirow[b]{2}{*}{ Kriteria } & \multicolumn{4}{|c|}{ Puskesmas } \\
\hline & ISO $(n=92)$ & Non-ISO $(\mathrm{n}=92)$ & p-value & Jenis Analisis \\
\hline Kepatuhan Tinggi $($ Skor $=8)$ & $16(17,4 \%)$ & $22(24 \%)$ & & \\
\hline Kepatuhan Sedang $($ Skor $=6-7)$ & $43(46,7 \%)$ & $40(43,5 \%)$ & $\begin{array}{l}0,319 \\
\text { NS }\end{array}$ & Kruskall \\
\hline Kepatuhan Rendah $($ Skor $=0-5)$ & $33(35,9 \%)$ & $30(32,5 \%)$ & & \\
\hline
\end{tabular}

Keterangan: $\mathrm{n}=$ jumlah responden; $\mathrm{NS}=$ not significant (tidak signifikan)

Tabel 5. Kejadian Adverse Drug Reaction (ADR)

\begin{tabular}{lccc}
\hline \multirow{2}{*}{ Parameter } & \multicolumn{3}{c}{ Puskesmas } \\
\cline { 2 - 3 } & ISO $(\mathbf{n = 9 2 )}$ & Non-ISO (n= 92) & Jenis Analisis \\
\hline Terjadi ADR & $0(0 \%)$ & $0(0 \%)$ & NA
\end{tabular}

Keterangan: $\mathrm{n}=\mathrm{jumlah}$ responden; NS=not significant (tidak signifikan); NA=not available

\section{d. Kepuasan Responden Terhadap Pelayanan Kefarmasian}

Berdasarkan hasil observasi terhadap tingkat kepuasan responden dengan menggunakan 8 kriteria dimensi yang tertuang dalam kuisioner dari Permenkes RI no 74 Tahun 2016, menunjukkan hasil bahwa kepuasan pasien pada puskesmas ISO dan non-ISO tidak berbeda signifikan ( $>0,05)$. Hal ini mengilustrasikan bahwa pasien memiliki tingkat kepuasan yang serupa terhadap pelayanan kesehatan di puskesmas berstandar ISO maupun nonISO sesuai dengan 8 dimensi yang terevaluasi tersebut. Hasil analisis lebih terperinci disajikan pada tabel 6 hingga 13 . Temuan yang menarik dari studi ini adalah puskesmas non-ISO di Kota Denpasar sangat kompetitif dalam memberikan pelayanan terbaik bagi masyarakat.

Tabel 6. Hasil Kepuasan Pasien Terhadap Dimensi Ketanggapan Tenaga Kefarmasian Terhadap Pasien

\begin{tabular}{|c|c|c|c|c|c|}
\hline No & Kategori Kepuasan & ISO $(n=92)$ & Non-ISO $(n=92)$ & p-value & Jenis Analisis \\
\hline 1 & Sangat Puas & $50(54,35 \%)$ & $45(48,91 \%)$ & \multirow{3}{*}{$\begin{array}{c}1,000 \\
\mathrm{NS}\end{array}$} & \multirow{3}{*}{ Kruskall Wallis } \\
\hline 2 & Puas & $42(45,65 \%)$ & $47(51,09 \%)$ & & \\
\hline 3 & Tidak Puas & $0(0 \%)$ & $0(0 \%)$ & & \\
\hline
\end{tabular}

Keterangan: $\mathrm{n}=\mathrm{jumlah}$ responden; $\mathrm{NS}=$ not significant (tidak signifikan) 
Tabel 7. Hasil Kepuasan Pasien Terhadap Dimensi Keramahan Tenaga Kefarmasian Terhadap Pasien

\begin{tabular}{|c|c|c|c|c|c|}
\hline No & Kategori Kepuasan & ISO $(n=92)$ & Non-ISO $(n=92)$ & p- value & Jenis Analisis \\
\hline 1 & Sangat Puas & $60(65,2 \%)$ & $46(50 \%)$ & \multirow{3}{*}{$\begin{array}{c}1,000 \\
\mathrm{NS}\end{array}$} & \multirow{3}{*}{ Kruskall Wallis } \\
\hline 2 & Puas & $32(34,8 \%)$ & $46(50 \%)$ & & \\
\hline 3 & Tidak Puas & $0(0 \%)$ & $0(0 \%)$ & & \\
\hline
\end{tabular}

Keterangan: $\mathrm{n}=\mathrm{jumlah}$ responden; $\mathrm{NS}=$ not significant (tidak signifikan)

Tabel 8. Hasil Kepuasan Pasien Terhadap Dimensi Kejelasan Tenaga Kefarmasian Memberikan Informasi Obat

\begin{tabular}{|c|c|c|c|c|c|}
\hline No & Kategori Kepuasan & ISO $(n=92)$ & Non-ISO $(n=92)$ & p- value & Jenis Analisis \\
\hline 1 & Sangat Puas & $49(53,27 \%)$ & $50(54,35 \%)$ & \multirow{3}{*}{$\begin{array}{c}1,000 \\
\mathrm{NS}\end{array}$} & \multirow{3}{*}{ Kruskall Wallis } \\
\hline 2 & Puas & $43(39,56 \%)$ & $42(45,65 \%)$ & & \\
\hline 3 & Tidak Puas & $0(0 \%)$ & $0(0 \%)$ & & \\
\hline
\end{tabular}

Keterangan: $\mathrm{n}=$ jumlah responden; $\mathrm{NS}=$ not significant (tidak signifikan)

Tabel 9. Hasil Kepuasan Pasien Terhadap Dimensi Kecepatan Pelayanan Obat

\begin{tabular}{|c|c|c|c|c|c|}
\hline No & Kategori Kepuasan & ISO $(n=92)$ & Non-ISO $(n=92)$ & p- value & Jenis Analisis \\
\hline 1 & Sangat Puas & $50(54,35 \%)$ & $45(48,9 \%)$ & \multirow{3}{*}{$\begin{array}{c}1,000 \\
\mathrm{NS}\end{array}$} & \multirow{3}{*}{ Kruskall Wallis } \\
\hline 2 & Puas & $42(45,65 \%)$ & $47(51,1 \%)$ & & \\
\hline 3 & Tidak Puas & $0(0 \%)$ & $0(0 \%)$ & & \\
\hline
\end{tabular}

Keterangan: $\mathrm{n}=$ jumlah responden; $\mathrm{NS}=$ not significant (tidak signifikan)

Tabel 10. Hasil Kepuasan Pasien Terhadap Dimensi Kelengkapan Obat dan Alat Kesehatan

\begin{tabular}{|c|c|c|c|c|c|}
\hline No & Kategori Kepuasan & ISO $(n=92)$ & Non-ISO $(n=92)$ & p- value & Jenis Analisis \\
\hline 1 & Sangat Puas & $47(51,09 \%)$ & $40(43,48 \%)$ & \multirow{3}{*}{$\begin{array}{c}0,513 \\
\text { NS }\end{array}$} & \multirow{3}{*}{ Kruskall Wallis } \\
\hline 2 & Puas & $45(48,91 \%)$ & $39(42,4 \%)$ & & \\
\hline 3 & Tidak Puas & $0(0 \%)$ & $3(32,6 \%)$ & & \\
\hline
\end{tabular}

Keterangan: $\mathrm{n}=$ jumlah responden; $\mathrm{NS}=$ not significant (tidak signifikan)

Tabel 11. Hasil Kepuasan Pasien Terhadap Dimensi Kenyamanan Ruang Tunggu

\begin{tabular}{|c|c|c|c|c|c|}
\hline No & Kategori Kepuasan & ISO $(n=92)$ & Non-ISO $(\mathrm{n}=92)$ & p-value & Jenis Analisis \\
\hline 1 & Sangat Puas & $35(38,05 \%)$ & $70(76,09 \%)$ & \multirow{3}{*}{$\begin{array}{c}0,827 \\
\mathrm{NS}\end{array}$} & \multirow{3}{*}{ Kruskall Wallis } \\
\hline 2 & Puas & $53(57,60 \%)$ & $22(23,91 \%)$ & & \\
\hline 3 & Tidak Puas & $4(4,35 \%)$ & $0(0 \%)$ & & \\
\hline
\end{tabular}

Keterangan: $\mathrm{n}=\mathrm{jumlah}$ responden; $\mathrm{NS}=$ not significant (tidak signifikan)

Tabel 12. Hasil Kepuasan Pasien Terhadap Dimensi Kebersihan Ruang Tunggu

\begin{tabular}{|c|c|c|c|c|c|}
\hline No & Kategori Kepuasan & ISO $(n=92)$ & Non-ISO $(n=92)$ & p- value & Jenis Analisis \\
\hline 1 & Sangat Puas & $40(43,48 \%)$ & $70(76,09 \%)$ & \multirow{3}{*}{$\begin{array}{c}0,827 \\
\mathrm{NS}\end{array}$} & \multirow{3}{*}{ Kruskall Wallis } \\
\hline 2 & Puas & $50(54,35 \%)$ & $22(23,91 \%)$ & & \\
\hline 3 & Tidak Puas & $2(2,17 \%)$ & $0(0 \%)$ & & \\
\hline
\end{tabular}

Keterangan: $\mathrm{n}=$ jumlah responden; $\mathrm{NS}=$ not significant (tidak signifikan)

Tabel 13. Hasil Kepuasan Pasien Terhadap Dimensi Ketersediaan Brosur, Leaflet, Poster Sebagai Informasi Obat/Kesehatan

\begin{tabular}{cccccc}
\hline No & Kategori Kepuasan & ISO $(\mathbf{n = 9 2})$ & Non-ISO $(\mathbf{n}=\mathbf{9 2})$ & \multirow{2}{*}{ p- value } & Jenis Analisis \\
\cline { 1 - 4 } 1 & Sangat Puas & $47(51,09 \%)$ & $50(54,35 \%)$ & \multirow{2}{*}{0,827} & \multirow{2}{*}{ Kruskall Wallis } \\
\cline { 1 - 5 } 2 & Puas & $45(48,91 \%)$ & $42(45,65 \%)$ & \multirow{2}{*}{ NS } & \\
\cline { 1 - 5 } 3 & Tidak Puas & $0(0 \%)$ & &
\end{tabular}

Keterangan: $\mathrm{n}=$ jumlah responden; $\mathrm{NS}=$ not significant (tidak signifikan)

\section{PEMBAHASAN}

Waktu tunggu pelayanan obat atas resep dokter merupakan salah satu indikator yang dapat digunakan untuk melihat suatu mutu pelayanan kefarmasian di Puskesmas. Puskesmas ISO tampak lebih unggul dalam variabel ini jika dibandingkan puskesmas non-ISO. 
Komponen ISO 9001:2008 yang berperan pada peningkatan mutu ini adalah klausul 5.4.1 yaitu sasaran mutu yang terukur dan konsisten dengan kebijakan mutu (Gasperzs, 2009). Setiap Puskesmas ISO telah menetapkan sasaran mutu yang sudah disepakati bersama. Sasaran mutu ini mengharuskan petugas Apotek untuk menyelesaikan obat non racikan kurang dari 3 menit. Hal inilah yang tidak dimiliki oleh Puskesmas Non-ISO, sehingga tidak ada penilaian terhadap diri sendiri pada indikator kecepatan pelayanan penyiapan obat di Apotek Puskesmas Non-ISO. Hingga saat ini Peraturan Menteri Kesehatan No. 74 Tahun 2016 tentang Standar Pelayanan Kefarmasian di Puskesmas tidak mengatur lama waktu tunggu pelayanan obat atas resep dokter di Puskesmas sehingga tidak terdapatnya aturan khusus yang meregulasi maksimal waktu tunggu pasien secara Nasional.

Observasi terhadap Drug Related Problem dilakukan hanya melihat tiga parameter antara lain kejadian interaksi obat, tingkat kepatuhan terapi responden dan Adverse Drug Reaction. Interaksi yang terjadi berdasarkan Pharmaceutical Care Network Europe Foundation V6.2 termasuk klasifikasi P1.3 yakni kombinasi obat-obatan atau obat-makanan tidak tepat termasuk kejadian interaksi obat. Pada Puskesmas ISO terdapat $11,96 \%$ dan pada Puskesmas Non-ISO 20,66\% kasus interaksi obat dimana interaksi yang terjadi masih dalam kategori monitoring closely dan minor. Interaksi ini bukan merupakan interaksi yang berbahaya dan masih dapat diberikan dengan pengawasan Dokter ataupun Apoteker. Sedangkan tingkat kepatuhan pasien yang ditunjukkan dari skor kepatuhan diperoleh dari jawaban kuisioner MMAS pada kategori ISO dan Non-ISO yaitu pasien yang memiliki kepatuhan tinggi dengan nilai skor 8 pada Puskesmas ISO yakni $17,4 \%$ dan Non-ISO $24 \%$, pasien yang memiliki kepatuhan sedang dengan nilai skor 6-7 pada Puskesmas ISO yakni 43,46\% dan NonISO $40 \%$, pasien yang memiliki kepatuhan rendah dengan nilai skor 0-5 pada Puskesmas ISO 35,9\% dan Non-ISO $32,5 \%$. Kepatuhan pengobatan yang rendah dapat mengakibatkan peningkatan risiko biaya perawatan, peningkatan penyakit komplikasi dan risiko rawat inap. Mengidentifikasi pasien yang tidak patuh dalam pengobatan rawat jalan penting agar dapat melaksanakan terapi dengan efektif (Srikartika, 2016). Drug Related Problem selanjutnya yakni Adverse Drug Reaction (ADR) atau reaksi obat yang merugikan. Berdasarkan hasil penelitian tidak terjadi ADR baik di Puskesmas ISO maupun NonISO. Berdasarkan hasil persentase kedua Puskesmas yakni 0\% kejadian ADR yang artinya tidak ada reaksi obat yang merugikan terhadap pasien.

Menurut Kemenpan No. 25 tahun 2004 Kepuasan pelayanan adalah hasil pendapat dan penilaian masyarakat terhadap kinerja pelayanan yang diberikan oleh aparatur penyelenggara pelayanan publik. Dengan demikian pelayanan publik dapat dikatakan baik apabila masyarakat mendapatkan pelayanan dengan prosedur yang mudah, biaya murah, waktu yang cepat dan mendapat sedikit atau bahkan tidak ada keluhan dari masyarakat. Berdasarkan hasil penelitian pengukuran kepuasan pasien dengan 8 dimensi dalam kuisioner tingkat kepuasan yang diambil dari Permenkes No 74 tahun 2016 tentang Standar Pelayanan Kefarmasian di Puskesmas menunjukkan bahwa tidak terdapat perbedaan antara Puskesmas ISO dan Non-ISO. Tidak terdapatnya perbedaan kepuasan antara Puskesmas ISO dan Non-ISO dikarenakan semua Puskesmas di Kota Denpasar saat ini sudah melakukan Akreditasi sehingga Puskesmas memiliki mutu pelayanan yang sama. Seluruh puskesma di Kota Denpasar telah diwajibkan mengikuti akreditasi sesuai dengan kebijakan pemerintah Kota Denpasar. Puskesmas tempat peneliti melakukan pengambilan data, merupakan puskesmas yang sama-sama telah melakukan akreditasi pada tahun 2017 gan predikat "Utama". Hal ini 
merupakan salah satu faktor yang menyebabkan tidak terdapatnya perbedaan kejadian DRP dan kepuasan pasien antara kategori ISO dan Non-ISO.

\section{KESIMPULAN}

Puskesmas berstandar ISO di Kota Denpasar memiliki keunggulan dalam hal waktu tunggu pelayanan obat atas resep dokter yang lebih cepat dibandingkan dengan puskesmas non-ISO, akan tetapi puskesmas non-ISO juga terbukti kompetitif dengan menunjukkan persamaan kualitas layanan terhadap puskesmas ISO pada luaran kejadian Drug Related Problem (DRP), dan kepuasan pasien.

\section{UCAPAN TERIMA KASIH}

Terimakasih penulis ucapkan kepada seluruh staf dan dosen di lingkungan Prodi Farmasi Institut Ilmu Kesehatan Medika Persada Bali dan Prodi Farmasi, Fakultas MIPA, Universitas Udayana yang membantu penyelesaian penelitian ini.

\section{DAFTAR PUSTAKA}

Aryani, F., Juniati, A., Husnawati, 2016.

Sistem Pengelolaan Obat Di Puskemas

Di Kecamatan Rambah Samo Kabupaten Rokan Hulu - Riau. 2016 Vol 13.

Keputusan Menteri Pedayagunaan Aparatur Negara No 25 Tahun 2004. Pedoman Umum Penyusunan Indeks Kepuasan Masyarakat Unit Pelayanan Instansi Pemerintah, Jakarta.

Niquille, A., and Bugnon, O., 2010, Relationship Between Drug-Related Problems and health outcomes: a crosssectional study among cardiovascular patients, Pharmacy World \& Science, 32: 512-519.

Nugraheni, 2017. Gambaran Waktu Tunggu Pasien dan Mutu Pelayanan Rawat Jalan di Poli Umum UPTD Puskesmas Pesantren 1 Kota Kediri Tahun 2017. Vol 4.
Peraturan Menteri Kesehatan Republik Indonesia, 2014. Pedoman Pelaksanaan Program Jaminan Kesehatan Nasional. Peraturan Menteri Kesehatan Republik Indonesia Nomor 28 Tahun 2014. Jakarta.

Peraturan Menteri Kesehatan, 2016. Standar Pelayanan Kefarmasian di Puskesmas. Peraturan Menteri Kesehatan Republik Indonesia Nomor 74 Tahun 2016. Jakarta.

Srikartika, 2016. Analisis Faktor yang Mempengaruhi Kepatuhan Penggunaan Obat Pasien Diabetes Melitus Tipe 2. Jakarta. 